\title{
3. Translating the musical image: case studies of expert musicians
}

\author{
Freya Bailes
}

There is more to music than the production and perception of real sounds; musical experience also involves musical thought through imagining and mentally re-presenting sounds. This can occur unintentionally, as in the phenomenon often called 'tune on the brain'. Alternatively, imaging music can be an involuntary corollary of musical activity, such as anticipating the next track on an album while listening to music or working towards an ideal musical sound in performance based on internally 'hearing' how it should sound. Finally, a mental image of music can be deliberate, as in the 'silent' analysis of a musical score or the auralisation of sound in harmony and counterpoint exercises.

How does musical thought in the form of musical imagery - a mental image of how the music should sound - translate to musical production? Musical imagery is the conscious experience of an internal representation of music, or inner hearing. Various definitions of imagery have been offered. In the auditory domain, Intons-Peterson (1992:46) describes it as the introspective persistence of an auditory experience, including one constructed from components drawn from long-term memory, in the absence of direct sensory instigation of that experience'. Musical imagery is a production of the mind's ear. It can differ importantly as an experience from the internal processes that channel and interpret any real incoming sensory information, otherwise known as perception. Imagination encompasses imagery, being 'the faculty or action of producing mental images of what is not present or in one's own experience' (Collins New English Dictionary 1997). The other definition of imagination (from the same source) as 'creative mental ability' presents imagery as a key ingredient in creative thought. Seashore (1938:161) makes a link between imagery and creation when he speculates that 'perhaps the most outstanding mark of the musical mind is auditory imagery, the capacity to hear music in recall, in creative work, and to supplement the actual physical sounds in musical hearing'. Robertson (1996:20) argues that 'we must accept that memory and a beautifully formed musical imagination are the prime factors in music making'.

Musical imagery has particular importance for musicians, functioning in creation, performance, auralisation, recollection and anticipation. Examples of its assumed occurrence include a performer developing an interpretation in her or his head, a conductor doing silent score reading in the absence of any instrument and a composer imaging new sounds or new combinations of sound. We know 
surprisingly little about the phenomenon of musical imagery, however, due in part to a reliance on introspection or inference based on a translation of the image into observable sound. What do expert musicians say about their imagery? For example, how important and how prevalent is musical imaging in expert musical activity, and how does it translate to and from perception? This chapter investigates these questions, with respect to three professional musicians in Western classical music: a composer, a pianist and a profoundly deaf organist. These musicians discuss the relationship of their mental representations of music to the music they perceive. First, an examination of existing research into the translation of image to sound, and sound to image, will be presented here.

\section{Translating image to sound}

The most obvious starting point when considering the translation of an auditory image to sound is the task of a composer. There is no shortage of anecdotal reports concerning the musical imagery of famous composers such as Beethoven, Stravinsky and Elgar. Mountain (2001:271-88) and Retra (1999) have attempted to undertake a more systematic understanding of the subject. For instance, Retra designed a study in which composers were asked to provide a verbal commentary on a composition task away from an instrument. The purpose was to investigate the nature of mental representation in the composition process.

Inspiration in composition is often taken to be synonymous with musical imagery and 'the myths that surround the one have confused investigation of the other' (Mountain 2001:273). One of these myths is that inspiration takes the form of a complete and pure auditory image to be translated in a sequential manner from the mind to paper. Mountain's evidence suggests that, in reality, composers are more likely to have been mentally working on music for a while, modifying and developing an image rather than transcribing one in virgin form. Harvey (1999) provides a comprehensive discussion on the subject of musical inspiration. Drawing on the reports of composers including Mahler, Dukas, Elgar, Boulez, Maxwell Davies, Schumann, Ligeti, Hindemith and Rubbra, he writes that the unconscious is clearly capable of reordering mental impressions to find solutions to compositional difficulties, without any need for conscious thought' (Harvey 1999:22). Penrose (1999) formulates a theory that creative thinkers unconsciously put up ideas for contemplation but consciously eliminate those that are redundant. Retra's (1999) conclusions are similar to this. She found that the composers in her study seemed to use imagery in compositional decision making as a means of holding information in conscious attention, inwardly 'hearing' it in what was metaphorically termed the 'mind's ear'. Mountain (2001:275-6) describes a similar intermediary role of mental imagery towards the final stages of musical composition: ' $[\mathrm{t}]$ he vividness of the auditory image is...necessary...so that it can be clearly maintained and referred to during the sometimes tedious procedure of notation.' 
The alternation between unconscious and conscious thought seems to be at the root of many misconceptions regarding the role of inspiration and the role of assimilation. A chronological dimension might mean that composing 'traces a path from the intangible imagination to the tangible reality of a created work' (Saxton 1998:6). Imagination is more than imaging, involving a degree of creativity over mere visualising or experiencing a ready-made copy. According to this, musical imagery might represent an intermediary point in translation between imagination and what Saxton (1998) describes as the 'aural detection' stages of creation. The process of developing a compositional idea implies a musical imagination, musical memory and the ability to alter and mentally rehearse an image.

Remarkably little research on musical imagery has looked at the translation of image to sound in performance, with the exception of Brodsky et al. (1999:370-92), who explored the inner hearing of orchestral musicians. Kvifte (2001:219-35) also explores imagery for performing musicians, describing the importance of mental imagery for the memory of form in Norwegian Hardingfiddle music. The author's main concern is to determine 'the relation between observed formal structure and possible internal images of them' (Kvifte 2001:219-20). In other words, the interest is in understanding what information about the performer's guiding mental image can be gained indirectly from their observable performance. This assumes a direct translation from mental imagery to overt behaviour, describing a feedback between one and the other in the process of performance.

In Western classical music, there is a tradition of translating visual and auditory imagery to sound when performing from memory. Marek reports that Toscanini was renowned for his musical memory and the veridical nature of his imagery:

His memory was strengthened by what I may call the 'mind's ear', meaning the ability to hear a composition by reading it. That ability is essential to a conductor, but Toscanini possessed it to an amazing degree. He had but to glance at a page of complex music, his glance seemingly casual, and he heard the page both horizontally and vertically in his imagination. (Marek 1982:416)

\section{Translating sound to image}

Where does the musical image come from? A translation occurs from the perception of sound to the creation of a mental re-presentation of that sound, including the conscious auditory image. Musical composition is not purely endogenous, requiring as it does the initial perception of constituent sound material. Even in Western classical music, in which written notation might seem to be the principal carrier of musical information, 'Western art music is in fact dependent upon an "oral" transmission of performance tradition' (Godøy and 
Jørgensen 2001:182). Great musical performers convey information additional to the musical score through the shared communication of a detailed musical image. Marek (1982:415) believes that 'retention of minutiae is an attribute of the interpretive artist; it lies at the base of performance, and it can be trained'. It is important to note the emphasis on the retention of perceived sound as a foundation for creative interpretation and the supposed potential to develop this skill.

\section{Musical essence}

'Take out the image from the musical mind and you take out its very essence' (Seashore 1938:6). Some musical traditions, however, are more dependent on auralisation than others. For example, consciously imaging sound away from a musical instrument (be that a violin, voice, CD player or computer) might feature less in improvisation or electro-acoustic practice than in the performance of a folk melody from memory. Moreover, some sound dimensions seem to be more susceptible to inclusion in an auditory mental image than others: in a sampling study of the occurrence of spontaneous musical imagery (Bailes 2006), I found that participants were more likely to image melody and song lyrics than harmony, timbre and expressive features of music. Intons-Peterson $(1980,1992)$ explored auditory imagery of environmental sounds in laboratory conditions and also found that timbral and dynamic dimensions seemed to be optional rather than essential to a conscious image. Harmony, timbre, dynamics and musical expression are, however, meaningful dimensions of musical experience. It would be wrong to strip down the notion of musical essence to those dimensions of auditory experience that can be mentally re-presented in consciousness. Nevertheless, translating from image to sound, it seems likely that musical dimensions important to the musical imagery of expert musicians would also be described as significant to the sounding of music. A content analysis of interviews with musical experts might reveal descriptions of musical dimensions important to image and sound.

\section{Case studies}

A semi-structured interview technique was employed that was designed to capture the individual experiences of the interviewees. While the respondents were selected because of their activities as professional musicians, the intention was not that they be considered representative of a wider musical population. The interviews reported here are necessarily limited by the musical and cultural backgrounds of interviewer and interviewees. Nevertheless, the focus on the experience of classically trained musicians represents a relevant viewpoint, coming from a tradition that promotes a key role for musical imagery.

The purpose of the interview was to explore emergent themes concerning the relationship of imagery to perception in musical activity and to allow the 
respondents to express their own accounts of their imagery experience. The interview schedule differed slightly for each respondent and was used as a prompt rather than a rigid set of questions. The aim was to encourage respondent-led discussion, albeit within loosely defined areas of researcher interest.

Interviews lasted between one and three hours. They were recorded with the permission of the respondents and later transcribed for thematic analysis. Each case study was analysed separately, examining the material repeatedly and systematically in order to determine emerging themes. Ultimately, a comparison of the common themes across the respondents was formally made (Bailes 2002). Common analyses relevant to translation of the image, across all three individuals, will be presented here.

\section{Respondent profiles}

Table 3.1 summarises the biographical details of each respondent. The broad areas addressed with each respondent are listed, along with the key emergent themes arising from an analysis of each interview.

\section{Table 3.1 Respondent profiles}

\begin{tabular}{ll}
\hline NG & \\
\hline Biographical details & Composer. \\
& Teaches in the music department of a \\
& university in the United Kingdom. \\
& Experienced in directing contemporary \\
& music and in piano performance. \\
& Studied composition with Bernard \\
& Rands and David Blake. \\
& Musical background, composition \\
& process, teaching, directing \\
& contemporary music. \\
Interview questions & Differences between imaging and \\
& imagining music, the respective \\
& limitations of imaging and perceiving \\
Emergent themes* & music, conceptual flexibility, musical \\
& meaning, musical familiarity.
\end{tabular}


HP

Biographical details

Interview questions

Emergent themes*
Pianist.

Teaches in the music department of a university in the United Kingdom.

Experienced in conducting.

Studied with Cyril Smith and Nadia Boulanger, and worked with Messiaen.

Ideal working method of a performing pianist, including the importance of mental preparation, musical training, role as a teacher, aural skills.

Definition and centrality of a guiding 'conception', importance of formulating detailed thoughts about a piece before hearing it, balance in mental preparation, ideals and realities, conceptual flexibility, tricks to develop auditory perception.

WP

Biographical details

Organist and pianist.

Also experienced in choir conducting.

Has congenital hearing loss and has been profoundly deaf since age seven.

Works as a signer for the deaf in opera and musical performances. Runs a charity to assist in the musical education of deaf children.

Interview questions How he perceives music, nature of his musical imagery, performing, conducting, signing.

Emergent themes*

Reliance on musical score, awareness and observation, perceiving through imaging, the 'working out' of music, memorising, imagination.

\footnotetext{
${ }^{*}$ Many themes emerged from the dialogue, but only those pertaining to the translation of musical imagery and perception are discussed here.
} 


\section{Interview analyses and discussion}

\section{Loss and gain}

Translation from one language to another entails loss and gain. By virtue of no longer using the same word, expression or musical medium, some quality is lost, but there can be a gain through the new perspective afforded by the translation. In this way, Eco (2003) describes translation as a negotiation. For example, NG explained that translating sound to mental imagery inevitably involved a loss in the veridical nature of sound colour. For example, when asked to describe any surprising outcomes of finally hearing his compositions performed, he replied:

I've always felt that the colour comes up more vividly in real life, and it's always better than you imagine it's going to be...Timbres are also going to be that much brighter - at least that's what I find - than the way I imagine them. They're always a little bit kind of, a little bit hazy, you know? They're not quite as resonant as they are in real life.

All three respondents expressed in various ways the importance of flexibility in perceiving and imaging music. In composition, this meant a delicate balance of fixing a musical idea without it becoming irremediably 'stuck' in notation or perception. In performance, the flexibility lay in the conception, a schematic framework that allowed for image and perception change. For WP, there was a need to ensure that learning from the technique of others did not transfer to mere copying without room for interpretative variation. Similarly, NG and HP described situations in which over-familiarisation with perceived music could occur: for NG this might involve hearing a composition repeatedly and becoming indifferent to its potential to grow, while for HP this would be the unwanted influence of other performers' renditions or being ruled by physical factors before a mental conception had been created.

NG believed that in composition, musical imagery could function to retain the balance of conceptual freshness. When talking about the 'use' of imagery in electro-acoustic composition (a medium in which he had only occasionally written), NG explained that having perceived the same music repeatedly could lead to over-familiarity with the material:

An instrumental composer is imagining a performance or imagining a sort of idealised performance whereas the studio composer's hearing the real thing. And you can, in the studio, get bored with the material and feel that you need to produce more layers of activity to liven it up, whereas the listener coming to that afresh might find it very exciting.

It is true that a listener would rarely attend to a piece of music in as much detail as the composer. The composer's boredom from repeatedly hearing the material 
might be avoided by composing some of the work through imagery rather than perception.

Translation is more than mere transcription and requires imagination. There was general agreement as to the role of imagination in music making, with it differing slightly from imagery in its creative function of reaching beyond given material. Perceived or imaged representations of music might equally constitute this given material, so that imagination was related but separate. In composition, hands-on manipulation of sound might be a more fruitful source of imaginative development, though imagery might also help break free from learned material through its inadequacies as an exact mental representation of given music. NG found the metaphor of a faulty tape to be a useful means of describing musical imagery. The weakness of mental imagery as a faithful reproduction lends it value for experimentation and modification. In this case, a certain gain in creativity is afforded by the use of imagery in composition rather than perception.

For HP, the 'imaginative impulse' in musical performance was at risk of being stifled by overly perceiving rather than imaging music. For him, going beyond the given meant looking beyond the surface information in the score, without distraction from the given material of perception, in order to create new meaning. In piano performance, HP described the principal advantage of forming mental imagery before physically tackling new music as freedom from technical constraints. It was suggested to him, however, that mental states were just as prone to becoming fixed as physical ones. When he first adopted the method of mental preparation and imaging sound before playing it, he said that he did become 'locked' into his imagery and he had since learned to rely more on the conception than the strict auditory image. He explained that conceptions could be refined and modified in accordance with changing ideas:

The important thing that you don't want, or I don't want anyway, [is] a performance that is so completely planned and cut and dried in every detail that it has no possibility of further growth...I mean in a way a certain, if you like, imprecision has to be built into the business of being a musician.

HP goes to some lengths to balance flexible and stable dimensions of his performance approach by noting down his initial impressions of a piece for reference at a later date. The emphasis here, as elsewhere in his interview, was on using indirect methods to practise music, avoiding habit and maintaining a fresh perspective while deepening a musical understanding.

WP also spoke of imagination, as having had to establish an 'imaginative vocabulary' of timbre. Implicit in his use of the term is the notion of extending given material, as for him, timbral information is not presented aurally, but needs to be created through combining and extending proprioceptive, observed 
and analytical knowledge. Contrary to Marek's description of the oral tradition of learning the 'minutiae' of performance practice from listening to great performers, the two expert performers interviewed in the current research described quite different approaches to image formation. For HP, hearing examples of music he wished to perform was to be avoided in preference for a highly autonomous mental image of the music. For WP, musical perception concerned visual perception and hands-on experience of playing an instrument.

\section{Mediating the musical 'essence'}

Translating image to sound and sound to image implies at least a basic level of equivalence between the two phenomenal experiences. For example, where there is an intention to communicate musical imagery in sound, it can be hypothesised that the composer/performer will translate the most meaningful elements of the mental image. The elements reported to feature in $\mathrm{NG}^{\prime}$ s mental imagery seem to correspond with those meaningful to his concept of music. In fact, he deliberately pointed out this relationship, saying that musical imagery necessarily related to an individual composer's musical language. An example of this concerns what he considers to be good examples of timbral writing in the composition of others: '[i]t's partly to do with working with the instrument and getting the best out of the instrument...finding something which is so characteristic of the instrument that you can't imagine another instrument playing it...Some timbres seem absolutely right for particular situations.' NG reported a conversation he had with a colleague about whether harmony was experienced as part of the mental image for music, using the example of the slow movement from Rachmaninov's Symphony No. 2 in E Minor. His argument was that harmony was necessarily 'heard' as integral to musical meaning and his colleague's disagreement made him 'question his musicality'. When asked if there were any musical styles that he would find harder to internalise and remember, he explained that he could not create an image of the whole of Gruppen, ${ }^{1}$ but that as gesture was the main meaning of that music, so gesture constituted the aspects of sound he could hear in his mind's ear.

Essential to HP's musical understanding and method of approaching performance is the 'conception'. This can take the form of a mental musical image, but bears closer resemblance to a more abstract schema generated for each piece. Indeed, the conception might be understood to be a generative force behind an individual piece of music: essential to its musical understanding and able to accommodate surface-level changes. He compared the conception with the largely structural overview held by a novelist. Once clear in the mind, the conception acts as a form of imagined model against which to compare all perceived renditions. HP explained that 'I like to know what I'm aiming at, and then I will find the means to realise it'. 
For HP, it is important to maintain the ideal conception. For example, he described his reluctance to practise at the venue for his next concert because of the piano's inadequacies, which might tarnish his idealised image of the music. The physical inadequacy of the instrument is largely beyond his control, while the ideal conception of how the performance should go is not. While an ideal performance is difficult to achieve, 'you're never going to get it unless you've imagined it. But you'd be amazed what you can do if you have actually set Everest in front of you... [because] the other thing is you're motivated by your imaging. You want it. You're not satisfied with less.' This was in contrast with the neglect that HP observed in most people's inner hearing. He bemoaned what he described as the 'sticking plaster' approach to solving performance errors, whereby individual notes were physically repeated, rather than listening and imaging the desired sound before attempting a performance: 'I suppose the huge lesson that I learned from my teacher...Cyril Smith, whose thinking in this area was incredibly advanced, which is that...we want to lead our hands.'

As a professional pianist, HP was concerned with the memorisation (formation of a memory image) of music. He spoke of his approach to memorising music as a developmental trajectory. For him, rote learning was something suitable to a child's mind, but the more experienced a musician became, the more an understanding of musical meaning was important to the process of remembering. As the number of musical episodes that have been experienced increases, the more the semantic rather than the episodic quality is significant. Accordingly, HP increasingly found the semantic musical meaning and conception to be important in learning a piece of music. The implications of this are an increasingly analytical relation of the music to abstract musical knowledge.

WP described harmony as a salient musical feature, as it not only featured in his favourite musical moments, it seemed to elicit the strongest emotional response. When describing favourite moments in pieces of music, WP's description took the form of the analysis of modulations. Speaking of West Side Story, he says, 'I never get tired of listening to that. It's such an incredibly analytical piece of music.' Analytical structure features heavily as the essential component in describing his method of memorising a work. His musical memory is more structural than note level: 'When I say that I memorise a piece of music, I obviously don't memorise every single note...I suppose it's a pared down representation of the whole thing...I suppose I'm really aware of form in a way.'

It is impossible to know to what extent WP's aural imagery resembles that of a musician without a hearing impediment. In spite of his emphasis on an analytical grasp of score, he also describes his music in terms of an 'aural tape' playing in his mind. When asked whether he envisaged the score mentally when memorising music, he replied, 'No, I don't actually...It's like I have a tape in my head, and I'm playing the tape.' 
Schemata based on past experience mediate perception, so that each perceptual moment is a process of extracting information from the environment that is meaningful to the individual. The musicians in these studies described imagery comprising features that correlated directly with those features they found interesting and meaningful in perception. This is not unusual when considered alongside the reported imagery of some famous composers. Stravinsky continually stressed the important use of instrumental colour as an integral part of a musical idea. He presents the way to write effective instrumentation as comprising imagination and declarative knowledge about the instrument, stating that Berlioz had both aptitudes (Stravinsky and Craft 1979:29). Elgar also experienced instrumentation as part of the musical meaning of his composition:

The fact is I mentally hear the instruments, and when scoring put down what I feel that the sentiment of the words, if there be words, demands for the most perfect expression attainable. So far as I am concerned the thing is already complete in my mind: to make others feel it as I do is the trouble. If I could only write as fast as I think! (Quoted in Buckley 1912:87-8)

\section{The translation process}

The notion of balancing loss and gain in translation has already been outlined. All three interviewees described intentionally exploiting this property of the translation process to suit their needs. When questioned about the relative merits of writing down compositional ideas or guarding them as mental constructs, NG clearly articulated a need to balance fixing ideas and maintaining flexibility. Describing musical imagery, he explained:

If it's a playback mechanism you can't actually be certain that every time it's the same, and I think this is the beauty and the drawback to notation that it actually fixes a version. If you're unlucky, that version becomes something that you can't develop any further because it becomes so fixed you can't see any potential in it any more. It's definitive; it's complete. Whereas, you know, sometimes it's more valuable to try to keep the ideas fluid.

NG describes imagery in his composition less as a static mental copy of sound than a way to free the imagination in its departure from repetition and fixed musical detail. A 'casual listener' to his own musical imagery, NG might attempt to 'capture the drama':

I've got strategies for trying to get the music down quickly. I mean there are two distinct processes: one which is to try to write down the music that's going on in your head, and the other which is to project more music. So one is constructivist, if you like, and the other is trying to capture something on the wing. 
Giving an example of 'capturing music on the wing', NG described how in order to produce a 20-minute composition assignment as a student, he had once attempted to imagine music in real time for that period, but

[w] hat came out eventually at the end of that summer was richer than what I heard in my head. Because I hope that I built into it layers of meaning...layers of activity which the casual listener the first time round wouldn't have heard. And in that position I was of course the casual listener.

The composition process necessitates making something more of this inner sound, so that the product is greater and richer than the image. Composers might only rarely experience moments of inspiration in the form of a complete auditory image. Rather, an amalgamation of auditory knowledge, based on perceptual experience and the unconscious association of ideas, is likely to underpin the bulk of musical creation. Where a conscious image of sound can be of particular value is to present auditory information to the mind's ear for contemplation, selection or transcription.

HP envisaged the translation from conception to surface detail to be a continuing cyclical process, described as follows:

I think you start with a conception, but clearly when you work on the details, I mean they are conceived too, and will feed back into the wider conception which will be modified accordingly, and indeed they may be modified by the instrument which you're playing on, and even in performance itself by the performance, and so on.

Familiarity with music, through its repeated perception, is assumed to lead to a strong corresponding mental image. An ideal for HP, however, is to avoid excessive familiarity with the music he is working on. The reality of over-familiarity is described as a loss of freshness. A direct comparison can be made between this performer's desire to rejuvenate his musical ideas and NG's balancing of perception and imagery in order to maintain creative newness. For HP, over-familiarity in motor terms means that if you're so conditioned in your nervous system and so on, doing it just like this, you can't react anyway'.

$\mathrm{HP}^{\prime}$ 's extremity of isolating the mental preparation of a performance should be contrasted with his description of the balance needed to become what he described as 'a great pianist':

Everything has to be in balance. When things are in balance you're playing well, and when you're not playing well, when you've lost your form, whatever it is, it's just like golf or something like that, or tennis...it's usually almost always because there's some key area that you're neglecting, whether ear, or indeed the conception. 
This balance relates to the practicalities of managing repertoire as mental and physical preparation:

It seems to me in a way that every day you come to practise a piece, and if it's a very difficult piece you may have to practise it day after day after day, but still every day you have to bring some new imagination to it, because otherwise the work simply becomes kind of technical, and in some way divorced from the imaginative impulse.

HP also mentions balance as important to the work of a conductor in safeguarding a conception and accommodating any change brought about by individual performers.

I say the task of being a conductor is really...treading that particular tightrope, isn't it?... There has to be some kind of balance in a conductor's work, and so it is obviously with any kind of instrumentalist, there's a balance between your pre-rehearsal planning, or pre-practice planning, and then what you actually do. But essentially, of course, you're able to diagnose, correct, improve and so on because you do know what it is that you want.

The balance between mental and physical dimensions might change during the process of preparing to perform a piece, but the guiding conception, a fundamentally mental measure, is present throughout. HP described his own approach to performance as 'controlled imprecision', a phrase that exemplified the balance required between conscious and unconscious thought in a piece. Control needs to be introduced and this is a predominantly conscious phenomenon. Unwanted unconscious influence should be avoided: 'The fact that we may be unconsciously influenced in the early stages by what feels comfortable, or safe, or whatever, is bad.' For HP, it is a lesser concern that processes become automatic than that processes should result from mental thought rather than physical tendencies.

Holding an idealised performance in mind requires imagery, but acting on it requires a perceptual feedback mechanism. HP said that ideally, the formulation of a conception, and the subsequent ability to image the desired sound, would allow a performer to diagnose their own problems. 'It is unquestionably the only path towards radical improvement, and huge standards...I am convinced it is the only method...if there's a secret...Because it enables you to be your own teacher, your own doctor. You diagnose everything yourself.' Based on his own experience, HP outlined useful tricks for a performing pianist to develop their perception and imagery - for instance, anything that involved playing the music in a physically different way, such as hand swapping, would necessitate aural rather than kinaesthetic cohesion. Singing the more aurally insecure left hand 
of a piano part while playing the more melodic right hand would also guarantee a thorough aural knowledge of the music.

The translation process of sound to image and image to sound described by WP is unique to his experience as a deaf musician. He was asked whether he could imagine the different sound qualities of different instruments when he read the score. His response was positive and he was able to explain it in terms of firsthand experience in playing different instruments when he was younger. He spoke of having had the 'chance of feeling' the bass clarinet. Interestingly, he expressed a particular interest and ability in orchestrating music: 'Now by rights I shouldn't be able to do that, 'cause you need a good ear...You need to be able to tell what instruments will sound like when you combine them...I freely admit I didn't have an extensive knowledge of the workings of these instruments.'

WP attributes his ability in orchestration to a vivid imagination, explaining, 'I've tried playing different instruments, or being in close proximity to them you build up this imaginative vocabulary, for want of a better word. And somehow your brain just absorbs it.' Thus, imagination, more creative than imaging, plays a crucial role in the translation of timbral experience for WP.

When asked whether there had been any overt emphasis on imaging music in his musical training, WP replied that hadn't been the case, probably because he had relied on performed examples to learn. Really performing music forms a central part of $\mathrm{WP}^{\prime}$ s experiences. He has learned to play the organ through observation, yet he says:

Interestingly enough, I don't frequently have the image of somebody physically playing. If I look at a piece of music I don't imagine somebody sat [sic] at a keyboard and how they're going to finger it... That could be because every performance that you do has got to be unique in your own interpretation.

This final comment is illuminating, as it demonstrates flexibility required to accommodate individual interpretation. When asked whether WP deliberately listened to and attended the performances of others when preparing a piece for performance, he explained that he tended to imagine his own interpretation.

WP frequently described a process of 'working out' some aspect of music. He said, for instance, 'I don't find it difficult to work out the harmony and even the structure just from looking at it' and 'I prefer to sit down and work out my own'. WP relies on musical score in order to experience music, though he is unable to explain how he acquired his apparently detailed auralisation skills. Score reading combines with a general awareness and observation of musical situations, such that music for this organist is more clearly an amalgamation of sensory modalities than otherwise acknowledged in music perception. He also 
describes perception in imagery terms - for, to him, perceiving necessitates image formation and the two are part of the same process.

\section{Fluency within a given 'language'}

Successful translation requires fluency in both languages. The accurate translation of sound to image or image to sound equally entails fluency in both. Interviewees expressed different comfort levels with imagery and perception relative to their experience or practice in each. When asked whether practice in composition had affected his own image formation, NG replied, 'Yes, I think it must...I can't say that I'm tremendously confident that I'm better at it now than I was, but I suppose I must be.'

Practice in musical imagery for HP meant balancing fixed and fluid tempi, as he felt that performers should be able to image tempo 'and in a way be able to switch ideally effortlessly from one to another, from say a very fast tempo to a very slow tempo, and vice versa'. Freedom is an important theme for HP. In general, he reports that his mental imagery is not restricting but liberating, and that 'the marvellous thing about imaging is that I can fly anywhere I want to'. From that he goes on to say that physical limitations, time and ambition are the only factors that could prevent the communication of a perfect musical interpretation: 'I've no doubt that you could put... a lot of repertoire in front of me, and that I can inside myself imagine what Smith would have called a world-beating performance.' HP made it clear that for him, score reading was a more productive exercise than sight-reading at the piano, as this bypassed technical problems in favour of a well-founded musical interpretation. For this to be the case necessitates exceptionally fluent imaging skills.

The notional division between sound and image is irrelevant to WP. He explained that he relied entirely on the printed score, as listening to music 'doesn't mean anything, its just some abstract noise with no recognisable shape, no recognisable form'. He went on to exclaim, 'I just cannot imagine life without a score'. For $\mathrm{WP}$, score is the primary musical experience. How is WP able to translate score into a musical image given his lack of conscious aural memory and having been profoundly deaf from early childhood?

I never knowingly sat down and taught myself how to read a score. I always thought that that was something that anybody could do...It's not something I've knowingly learnt to do. I don't know whether that's been some sort of automatic compensation for my hearing loss, or the fact that I have to relate to what I see.

WP explained that scores differed in their difficulty of reading and subsequently in imaging them. Of a particularly dense score, he said, 'that's not to say I couldn't do it. If you gave me time I could sit there and work out what was going on.' His approach when presented with new score was to 'flick through 
it' to gain an overview and pick out important features. Given that the musical information represented in score is WP's primary access to music, it is unsurprising that an incomplete score is troubling to him:

If somebody gives me a lead sheet and some lyrics I don't feel confident at all. I find it so hard to do. Blood Brothers is an example. I've been signing Blood Brothers...for about six years now. They don't have a score. All I have is a vocal selection book so a vast amount of the time I've no idea what the band is doing.

WP reported difficulties in recreating music he had heard without a score. For instance, as a child, he heard Mahler's Symphony No. 8 in E Flat Major and only subsequently bought a recording and a score. He was then unable to re-experience the passage he had liked at first hearing, perhaps due to memory problems or perhaps because of a faulty original perception: 'What I imagined was happening and what was really happening may not have been the same thing.' WP proposed that a mismatch between perception and image could have occurred. He expresses this idea explicitly:

If I go to a concert or on the rare occasions I might listen to a piece of music without a score, but I do know what's going on, I can actually conjure up some kind of picture in my head, but when I get the score afterwards I find it bears no relation at all to what I thought I heard.

This is an example of perceiving music through imaging. Comparing a mental image with the score is, for WP, tantamount to comparing his mental image with a 'listening'.

\section{Conclusion}

The purpose of the case studies reported in this work was to gather detailed information about the perspective of individuals on the relationship of imagery to perception in professional musical life. Their experiences have been presented as forms of translation from image to sound and sound to image. The reader should note that in addition to the translational level of musical thought to sound, or sound to mental re-presentation, a number of interpretative levels have been superimposed on the interviewees' experience. Not only has the author translated the experience of the three musicians according to themes of translation, the interviewees were asked to reflect on how introspection and self-reporting affected the very experience of musical imagery during the interview process. NG commented on this and, as he did so, he described imaging L'Après-Midi d'un Faune, saying:

I suspect that it's to do with the sense of what in the textures you're listening to are most immediate... And I would suspect that trying to describe it to you would tend to make these layers drop away. So what's 
immediately retrievable will stay - so the flute will stay and the harp will stay at the beginning - but other things might drop away.

This presents imagery in the light of an ability to attend to different sounds much as might occur in perception. It is important as an indicator of how changes in introspective attention might alter the entire imagery process and represent an interpretative translation in themselves. This is a facet of a further level of translation described in the introduction-namely, the translation in musical process between unconscious and conscious thought.

The chapter began by asking how conscious musical thought, or musical imagery, translated to musical production. It is not within the scope of this work to consider the physical coordination involved in sound production. Instead, this research hopes to highlight the role of auditory imagery in planning musical production, and conversely as a translation from the perceptual experience of sound. Imagery and perception could be so intertwined as to appear inseparable. Certainly, for WP as a deaf musician, perceiving music necessitates the immediate formation of a musical mental image and imaging music through score reading constitutes perception. The musicians of this study, however, also drew certain fairly clear boundaries between image and sound. In translation terms, it is beneficial to retain a certain fluency in both 'languages', as each is essentially linked to an underlying conception or schematic framework, but each provides a complementary interpretation, unattainable in isolation. Imagery as described by the respondents might be an idealised musical representation, being held up as the perfect goal in performance. Perception might never live up to the exemplary image. This perspective imbues imagery with a freedom that cannot be matched in musical production. At the same time, imagery is acknowledged to be a flawed representation of perceptual experience.

In translating from one language to another, there is inevitably a negotiation between loss and gain. Saxton (1998:6) articulates the intricate negotiation of perception, imagery and imagination involved in composition, saying that '[f]or a composer, there exists continual two-way osmosis between the material itself and applied methods of treating the "received" musical ideas'. We have seen that perception or imagery can furnish these 'received' ideas, while imagination works to develop this, either consciously or unconsciously, to present in a new form. Perception and imagery are described as playing crucial roles with respect to the need for creative musicians to fix their ideas. This applies as much to performers as to composers. For instance, in accordance with the views of HP, Brendel (1976) says that when music is not easy to retain in memory, having to relearn it contributes to a fresh performance. Here the mental image is not a fixed 'master record' but is closer to a flexible conception. Musical imagery and musical sound might be expressed as translations that serve to 'augment the 
significance and expressivity' (Eco 2003:82) of musical experience. It is certainly difficult to conceive of the existence of one without the other. ${ }^{2}$

\section{References}

Bailes, Freya 2002, Musical imagery: hearing and imagining music, PhD dissertation, University of Sheffield, Sheffield.

Bailes, Freya 2006, 'The use of experience-sampling methods to monitor musical imagery in everyday life', Musicae Scientiae, vol. 10, no. 2, pp. 173-90.

Brendel, A. 1976, Musical Thoughts and Afterthoughts, Robson Books, London.

Brodsky, W., Henik, A., Rubinstein, B. and Zorman, M. 1999, 'Inner hearing among symphony orchestra musicians: intersectional differences of string-players versus wind-players', in S. W. Yi (ed.), Music, Mind, and Science, Seoul National University Press, Seoul, pp. 370-92.

Buckley, R. J. 1912, Sir Edward Elgar, Second edition, John Lane, London.

Collins New English Dictionary 1997, HarperCollins Publishers, United Kingdom.

Eco, Umberto 2003, Mouse or Rat? Translation as Negotiation, Weidenfeld \& Nicolson, London.

Godøy, R. I. and Jørgensen, H. (eds) 2001, Musical Imagery, Swets \& Zeitlinger, Lisse.

Harvey, J. 1999, Music and Inspiration, Faber and Faber, London and New York.

Intons-Peterson, M. J. 1980, 'The role of loudness in auditory imagery', Memory and Cognition, vol. 8, no. 5, pp. 385-93.

Intons-Peterson, M. J. 1992, 'Components of auditory imagery', in D. Reisberg (ed.), Auditory Imagery, Lawrence Erlbaum Associates, Hillsdale, NJ, pp. 45-71.

Kvifte, T. 2001, 'Images of form: an example from Norwegian Hardingfiddle music', in R. I. Godøy and H. Jørgensen (eds), Musical Imagery, Swets \& Zeitlinger, Lisse, pp. 219-35.

Marek, G. T. 1982, 'Toscanini's memory', in U. Neisser (ed.), Memory Observed: Remembering in natural contexts, W. H. Freeman and Co., San Francisco, pp. 414-17.

Mountain, R. 2001, 'Composers and imagery: myths and realities', in R. I. Godøy and H. Jørgensen (eds), Musical Imagery, Swets \& Zeitlinger, Lisse, pp. $271-88$.

Penrose, R. 1999, The Emperor's New Mind: Concerning computers, minds and the laws of physics, Oxford University Press, Oxford. 
Retra, J. 1999, An investigation into the musical imagery of contemporary composers, MA dissertation, University of Sheffield.

Robertson, P. 1996, Music and the Mind, Channel Four Television, London.

Saxton, R. 1998, 'The process of composition from detection to confection', in W. Thomas (ed.), Composition, Performance, Reception: Studies in the creative process in music, Aldershot, Ashgate, pp. 1-16.

Seashore, C. E. 1938, Psychology of Music, McGraw-Hill, London.

Stravinsky, I. and Craft, R. 1979, Conversations with Igor Stravinsky, Faber Music Ltd, London.

\section{Endnotes}

1 Gruppen (1955-57) is a piece for three orchestras by Stockhausen. The instrumentalists surround the audience on three sides and the music is characterised by the superimposition of independent tempi.

2 The research reported in this chapter is adapted from a portion of my doctoral work conducted at the University of Sheffield, United Kingdom, and supported by an Arts and Humanities Research Board scholarship. I wish to thank my interviewees for their generous participation in this research, as well as Karen Burland, Eric Clarke and Hazel Smith for comments on previous versions of this manuscript. 